This is an electronic reprint of the original article. This reprint may differ from the original in pagination and typographic detail.

Author(s): Mikkola, Tuija; Sipilä, Sarianna; Portegijs, Erja; Kallinen, Mauri; Alén, Markku; Kiviranta, Ilkka; Pekkonen, Mika; Heinonen, Ari

Title: Impaired geometric properties of tibia in older women with hip fracture history

Year: $\quad 2007$

Version:

Please cite the original version:

Mikkola, T., Sipilä, S., Portegijs, E., Kallinen, M., Alén, M., Kiviranta, I., Pekkonen, M., \& Heinonen, A. (2007). Impaired geometric properties of tibia in older women with hip fracture history. Osteoporosis International, 18(8), 1083-1090.

https://doi.org/10.1007/s00198-007-0352-x

All material supplied via JYX is protected by copyright and other intellectual property rights, and duplication or sale of all or part of any of the repository collections is not permitted, except that material may be duplicated by you for your research use or educational purposes in electronic or print form. You must obtain permission for any other use. Electronic or print copies may not be offered, whether for sale or otherwise to anyone who is not an authorised user. 


\section{Impaired Geometric Properties of Tibia in Older Women with Hip Fracture History}

Tuija Mikkola ${ }^{1}$, Sarianna Sipilä ${ }^{1}$, Erja Portegijs ${ }^{1}$, Mauri Kallinen ${ }^{2,3}$, Markku Alén ${ }^{1}$, Ilkka Kiviranta $^{2}$, Mika Pekkonen ${ }^{4}$, Ari Heinonen ${ }^{1}$

${ }^{1}$ Department of Health Sciences, University of Jyväskylä, Jyväskylä, Finland

${ }^{2}$ Central Finland Health Care District, Jyväskylä, Finland

${ }^{3}$ The GeroCenter Foundation for Research and Development, Jyväskylä, Finland

${ }^{4}$ Peurunka Medical Rehabilitation Center, Laukaa, Finland

\section{Corresponding author:}

Tuija Mikkola

University of Jyväskylä

Department of Health Sciences

P.O. Box 35 (Viveca)

FIN-40014 University of Jyväskylä

Finland

Tel. +358 142602149

Fax +358142604600

Email: tuija.mikkola@sport.jyu.fi

\section{MINI-ABSTRACT}

This study evaluated side-to-side differences in tibial mineral mass and geometry in women with previous hip fracture sustained on average 3.5 years earlier. Both tibial mineral mass and geometry were found to be reduced in the fractured leg. 


\begin{abstract}
Introduction The purpose of this study was to evaluate side-to-side differences in tibial mineral mass and geometry after hip fracture, and to assess the determinants of such differences.
\end{abstract}

Methods Thirty-eight 60- to 85-year-old women with a previous hip fracture and twenty-two same-aged control women without fractures participated in the study. Bone characteristics of the distal tibia and tibial shaft of both legs were assessed using pQCT in order to compare the side-to-side differences of tibias between the two groups.

Results The subjects with fracture history had significantly ( $\mathrm{p} \leq 0.05$, analysis of covariance) larger side-to-side differences than the controls in tibial shaft BMC (-4.9\% vs. $-0.5 \%)$, cortical area $(-5.2 \%$ vs. $0.1 \%)$ and polar moment of inertia $\left(\mathrm{I}_{\text {polar }}\right)(-5.6 \%$ vs. $-0.8 \%)$ and in distal tibia BMC (-5.1\% vs. $-1.4 \%)$ and $\mathrm{I}_{\text {polar }}(-7.5 \%$ vs. $-2.4 \%)$. In the fracture patients, the side-to-side differences in muscle characteristics explained 23 to $44 \%$ of the variances in the side-to-side differences in bone mass and geometry.

Conclusions Hip fracture results in reduced bone mass and impaired bone geometry in the tibia of the affected limb in older women. Muscle-induced loading may have a considerable role in the recovery of bone mineral mass and geometry after hip fracture.

Key words: aging, bone geometry, hip fracture, muscle, pQCT 


\section{INTRODUCTION}

Fractures in older people, especially hip fractures, are a major public health problem worldwide. Hip fractures cause increased morbidity and mortality [1], impose an economic burden on health services [2, 3] and lead to reduced health-related quality of life [3, 4]. Compared to those without fractures, persons with a previous hip fracture have a 2- to 3-fold higher risk of sustaining a subsequent fracture [5-7].

The increased risk of a repeat fracture may be partly caused by a decrease in the bone mineral mass of the affected limb. Bone mass declines in the affected limb after a fracture [8-12] and may result in a considerable side-to-side difference between the limbs [10,11, 13-16]. Part of this bone loss is thought to be caused by disuse of the affected limb following the injury [17]. If disuse is a significant determinant of post-traumatic bone loss, rehabilitation strategies could be developed in order to prevent deterioration of bone properties in the affected limb after fracture.

Previous studies on posttraumatic bone loss have concentrated mainly on areal bone mineral density (aBMD) measured with a DXA scanner [8, 9, 14, 15, 18-23]. Although the crosssectional geometry of bone has a large contribution to bone strength [24], the associations between lower limb fracture and bone geometry have been studied scarcely [25, 26]. In fact, adaptation to loading may occur in bone geometry without changes in aBMD or volumetric BMD $[27,28]$. Thus, investigation of changes that take place in bone geometry after hip fracture and factors that are associated with such changes gives new information on the mechanisms of post-traumatic bone loss. Therefore, the purpose of this study was to evaluate side-to-side differences in tibial mineral mass and geometry in older women with previous hip 
fracture, and to assess the mobility- and muscle-related determinants of such differences in bone. 


\section{MATERIALS AND METHODS}

\section{Subjects}

This study was a part of a larger randomized controlled study investigating the health, functional ability and rehabilitation of hip fracture patients. The patient records of Jyväskylä Central Hospital were utilized during 2004-2005 to recruit community-living 60-85-year-old men and women who had sustained a femoral neck or trochanteric fracture within 6 months to 7 years earlier and were living in the catchment area of Central Finland Health Care District. A letter informing about the study was sent to all patients who had no diagnosed dementia and no progressive severe illnesses $(n=452)$. A total of 193 patients responded of which 132, who expressed an initial interest, were interviewed by telephone to ensure that they conformed to the inclusion criteria of the larger study: able to move outside without assistance from other person and no neurological diseases or lower limb amputations. Altogether, 79 patients (54 women, 25 men) participated in the examinations. Also, a control group of 25 women and 6 men without previous hip fractures was recruited through advertisements in the catchment area of the same health care district as the hip fracture patients. In addition, in order to minimize the effect of other previous injuries, hip fracture patients who had a history of bilateral hip fracture, and also those patients and controls who had undergone hip or knee replacement surgery (other than due to hip fracture) or sustained other major lower limb traumas within 15 years prior to the examinations, were excluded (21 hip fracture patients and 4 controls). Consequently, the number of eligible men was small (20 hip fracture patients and 5 controls) and thus only women were selected for the analysis (38 hip fracture patients and 22 controls). Bone analysis of the tibia could be performed for 37 of the 38 measured hip fracture subjects and the analysis of the radius for 33 hip fracture subjects and 18 control 
subjects. The reasons for the rejection of the bone analyses were: an inaccurate measurement level in the tibia due to limited range of motion in the ankles of one subject, previous radius fractures at the measurement site and gross movement artefacts in the radius images. The study was approved by the ethics committee of the Central Finland Health Care District and the subjects gave their written informed consent prior to participating in the study.

\section{Measurements}

Bone and muscle characteristics were measured on the fractured and non-fractured side for the hip fracture patients and on the dominant and non-dominant side for the controls. The dominant leg of the control subjects was determined as the leg preferred for kicking a football.

\section{Medical examination}

The medical examination was performed by a physician and a nurse. Fracture status was confirmed and medical contraindications for participation in the measurements were evaluated. The presence of chronic diseases and current medication were documented according to a questionnaire, prescriptions and medical records. In the hip fracture group eight persons were using alendronate, one was using oral corticosteroid and one subject in each group was receiving hormone replacement therapy. Details on smoking habits were elicited by a questionnaire. One hip fracture patient was currently smoking and two hip fracture patients and one subject in the control group were former smokers. 


\section{Bone characteristics}

Distal tibia, tibial shaft and distal radius were scanned using peripheral quantitative computed tomography (pQCT) (XCT 2000, Stratec Medizintechnik GmbH). The distal tibia and tibial shaft of both lower limbs were scanned. The distal tibia was defined as $5 \%$ and tibial shaft as $55 \%$ of the measured tibial length proximal to the distal end plate. In addition, to analyze general bone status, the distal radius (4\% of the measured segment length) of the dominant arm was scanned. The voxel size was $0.8 \mathrm{~mm}$ in the measurements of tibia and $0.59 \mathrm{~mm}$ in the measurement of radius. Quality assurance measurements were performed daily. The analysis of the pQCT images was performed by software designed for cross-sectional CTimage analyses (Geanie 2.1, Commit; Ltd, Espoo, Finland). To separate the bone from the surrounding tissues, a density threshold of $169 \mathrm{mg} / \mathrm{cm}^{3}$ was used for the distal tibia and distal radius and $280 \mathrm{mg} / \mathrm{cm}^{3}$ for the tibial shaft. The threshold was set at $120 \mathrm{mg} / \mathrm{cm}^{3}$ if the abovementioned threshold was too high for the whole bone area to be included in the analysis (in the distal tibia this was done for 14 subjects with hip fracture and two control subjects, and in the distal radius for one subject with hip fracture and one control subject). However, in the distal tibia the same threshold was used for both legs. Separation of trabecular and cortical bone was performed in the distal tibia by peeling $30 \%$ from the outer edge of the bone's cross-sectional area and considering the remaining area as trabecular bone (S-mode) and in the tibial shaft by using a contour detection algorithm (automatic K-mode). Total crosssectional area (ToA, $\mathrm{mm}^{2}$, including the bone marrow area), bone mineral content (BMC, $\mathrm{mg} / \mathrm{mm})$, cortical volumetric bone mineral density $\left(\mathrm{CoD}, \mathrm{mg} / \mathrm{cm}^{3}\right)$, cortical cross-sectional area $\left(\mathrm{CoA}, \mathrm{mm}^{2}\right)$, and density weighted polar moment of inertia $\left(\mathrm{I}_{\text {polar }}, \mathrm{mg} \mathrm{cm}\right.$; reflects the bone’s resistance to bending and torsion) were analyzed for the tibial shaft. BMC, trabecular

volumetric bone mineral density $\left(\mathrm{TrD}, \mathrm{mg} / \mathrm{cm}^{3}\right)$, ToA and $\mathrm{I}_{\text {polar }}$ were determined for the distal tibia. For the distal radius only BMC was analyzed. BMC was calculated by multiplying the 
total volumetric bone mineral density by the total cross-sectional area (marrow excluded in the tibial shaft) and $1 \mathrm{~mm}$. The precision of pQCT measurements of BMC, TrD, CoD and $\mathrm{CoA}$ in these tibial sites has been reported to vary from 0.7 to $1.7 \mathrm{CV}_{\mathrm{rms}} \%$ (root mean square coefficient of variation percent) [29].

\section{Muscle cross-sectional area and maximal isometric strength}

The cross-sectional area of the lower leg muscles (muscle CSA) was measured from the pQCT scans of the 55\% site of the tibia. The muscle area was determined from the pQCT images utilizing Geanie 2.1 software by manually defining the boundaries between muscle and bone as well as muscle and subcutaneous fat.

Maximal isometric knee extension strength was measured from both sides in a sitting position using an adjustable dynamometer chair (Good Strength, Metitur, Palokka, Finland). The measurements were performed at a knee angle of $60^{\circ}$ from full extension with the ankle fastened by a belt to a strain-gauge system. The subjects were allowed to familiarize themselves with the method by doing two to three submaximal efforts. Three to five maximal efforts of 2-3 seconds, separated by 30 seconds rest, were conducted. During the measurements, the subjects were verbally encouraged to produce their maximum. For each subject, the best performance with the highest value was accepted as the result. In our laboratory, the coefficient of variation (CV) for the measurement of isometric knee extension strength is $6 \%$ [30].

\section{Maximal walking speed}

In a maximal walking test subjects were asked to walk 10 meters as fast as possible without compromising their safety. The subjects were allowed 3 meters for acceleration. Time was 
measured with photocells. The subjects were allowed to use their habitual walking aids. In our laboratory, CV for the measurement of walking speed is less than 5\% [30].

\section{Statistical analyses}

The data were analyzed with SPSS 12.0.1 software (SPSS Inc.). The differences between the groups in physical characteristics, i.e. age, weight, height, number of chronic diseases and radius BMC, were analyzed using t-test for independent samples. The side-to-side differences in bone variables, knee extension strength and muscle CSA between the legs were defined in the hip fracture patients as (fractured side - non-fractured side) / non-fractured side * 100\%, and in the controls as (dominant side - non-dominant side) / non-dominant side * $100 \%$, as BMC and cortical thickness have been found to be higher in the non-dominant than dominant leg in young men [31]. Comparison of the side-to-side differences in bone variables between the groups was made using the analysis of covariance (ANCOVA) with age and weight as covariates. In the hip fracture patients, the associations of age, time since fracture, side-to-side difference in isometric knee extension strength, side-to-side difference in muscle CSA, and maximal walking speed with those bone variables that showed significant side-to-side differences (compared to control group) were analyzed using Pearson’s correlation coefficient. Further, all the variables which correlated with the bone variables were entered as independent variables in linear regression models in which the side-to-side differences in the bone variables were dependent variables. The regression models were adjusted for time since fracture. The level of statistical significance was set at $\mathrm{p} \leq 0.05$. The observed difference between the groups in side-to-side difference in tibial shaft BMC on the given significance level provided a 85\% statistical power. Data are presented as mean (SD, standard deviation) and for the side-to-side differences in bone variables also 95\% confidence intervals are given. 


\section{RESULTS}

The hip fracture patients and controls did not differ significantly in mean age, body weight, height, number of chronic diseases or in mean radius BMC (Table 1). In the hip fracture patients, maximal isometric knee extension strength was on average $192 \mathrm{~N}$ in the fractured side and $223 \mathrm{~N}$ in the non-fractured side (side-to-side difference on average $-9.4 \%$ ). The muscle CSAs of the lower legs were $5260 \mathrm{~mm}^{2}$ and $5380 \mathrm{~mm}^{2}$, respectively $(-1.9 \%)$. In the control group knee extension strength was on average $295 \mathrm{~N}$ in the dominant side and $290 \mathrm{~N}$ in the non-dominant side (2.4\%) whereas the muscle CSAs were $6040 \mathrm{~mm}^{2}$ and $5960 \mathrm{~mm}^{2}$, respectively (1.2\%). Maximal walking speed was on average $1.2 \mathrm{~m} / \mathrm{s}$ in the hip fracture group and $1.8 \mathrm{~m} / \mathrm{s}$ in the control group.

The observed bone values and side-to-side differences for the tibia are given in Table 2. In the tibial shaft the hip fracture patients had statistically significantly larger side-to-side differences than the controls in BMC (-4.9\% vs. $-0.5 \%)$, CoA (-5.2\% vs. $0.1 \%)$ and $\mathrm{I}_{\text {polar }}(-$ 5.6\% vs. $-0.8 \%)$. There were no significant differences between the groups in ToA or CoD. In the distal tibia the hip fracture patients had significantly larger side-to-side differences in BMC (-5.1\% vs. $-1.4 \%)$ and $I_{\text {polar }}(-7.5 \%$ vs. $-2.4 \%)$, but no between-group differences were found in $\operatorname{TrD}$ or ToA. The hip fracture patients had lower absolute values in the non-fractured leg compared to the non-dominant leg of the control group in $\mathrm{BMC}$ and $\mathrm{CoA}$ in the tibial shaft and in BMC and TrD in the distal tibia $(\mathrm{p}=0.017-0.039)$.

In the hip fracture patients, side-to-side differences in knee extension strength and muscle CSA correlated significantly with most of the side-to-side differences in bone mineral mass and geometry (Table 3). However, age, weight, time since fracture or $10 \mathrm{~m}$ walking speed had 
no significant correlations with any side-to-side difference in the bone variables. In the regression analysis, side-to-side difference in knee extension strength and muscle CSA together explained $23 \%$ to $44 \%$ of the variance in the side-to-side differences in BMC and $I_{\text {polar }}$ of the distal tibia and tibial shaft and in the cortical area of the tibial shaft (Table 4). 


\section{DISCUSSION}

Our data showed that after hip fracture clear side-to-side differences occur in tibial bone characteristics due to impaired geometric properties and bone mineral mass in the tibia of the affected limb. However, hip fracture did not seem to affect the total area, cortical density or trabecular density of the tibia. In addition, we found significant associations between reductions in muscle characteristics and reductions in bone mineral mass and geometry in the affected limb.

Our findings concerning bone mineral content are in line with those of previous studies which have shown side-to-side differences ranging from $2 \%$ to $7 \%$ in DXA-derived aBMD after femoral shaft [14] and lower leg fractures $[15,20]$ several years after the injury. In the case of a lower limb fracture, the decline in aBMD seems to be steepest during the first 6 months following the injury $[8,9,32]$. During that time declines of $14 \%$ in the proximal tibia aBMD [9] and 19\% in the proximal tibia vBMD [12] of the fractured limb have been reported to take place. After the first year post-fracture bone mineral mass may increase but will not reach the prefracture level [20], leaving a permanent side-to-side difference between the limbs [14, 15]. The reductions in bone mineral mass and geometry of the fractured limb observed in the present study are likely to have been larger earlier in the patients' histories, as the hip fracture patients had sustained their fracture on average 3.5 years before the measurements.

In addition to large side-to-side differences, the hip fracture patients seemed to have systematically lower absolute values in bone mineral mass and geometry in both the fractured and non-fractured limb compared to the control subjects. In these patients it is possible that their fractures originated in an already low bone density and poor bone geometry prior to the 
fracture. However, because the bone mass was lower in the hip fracture patients than in the controls only in the lower limbs but not in the upper limbs, it seems more likely that the reductions in the non-fractured limb are also an outcome of the fracture. This is further supported by previous studies that have shown that after a fracture aBMD decreases not only in the fractured but also in the non-fractured limb $[8,19-21,23]$ at a rate that is higher than the normal age-related decline $[19,21]$. In addition, aBMD may remain at a reduced level in the non-fractured limb at least five to six years after a lower limb fracture [20, 22]. Therefore, estimating the decline in bone values of the fractured side by comparing it to the nonfractured side, may underestimate the true post fracture decline.

There was no reduction either in tibial shaft cortical density or distal tibia trabecular density in the fractured limb of the hip fracture patients. Because there was a reduction in distal tibia BMC but no marked reduction in trabecular density or trabecular area (not reported here), most of the decrease in BMC must have taken place in the remaining bone area. Due to the method of analysis (areal percentage separation) this area consisted of cortical bone together with a varied amount of trabecular bone next to the cortical wall. The reduction in BMC in this area may have been due to thinning of the cortical wall since cortical area rather than trabecular density has been found to diminish as a consequence of unloading in rats [33]. Unfortunately, we were unable to separate the cortical and trabecular compartments more precisely in the distal tibia because of the very thin cortical wall in most subjects. Our results on the cortical density of the shaft are supported by the studies by Bråten et al. and Terjesen et al. who found only small or no side-to-side differences in tibial shaft cortical density after femoral shaft fracture $[25,26]$. Changes in cortical density may not be the primary mechanism by which long bone shafts adapt to altered loading, as no differences seem to exist in cortical density between very differently loaded limbs, such as the dominant and non- 
dominant arm in racquet-sports players [27, 34]. After hip fracture, bone loss in the tibial shaft seems mainly to be due to endocortical resorption since in the affected limb the cortical area was clearly reduced while the total area of the affected limb was equal to that of the nonaffected limb.

The observed distinct reductions in bone geometry e.g. in cortical area and polar moment of inertia have to be considered clinically important. According to Russo et al. [35] annual decline in tibial shaft cortical area is approximately $1 \%$ and in minimum moment of inertia 0.5\% in 60-year-old and older women. Consequently, the deterioration in bone geometry in the fractured limb of our hip fracture subjects is several years ahead of the reported agerelated decline. On the other hand, it has been shown that in aging, the cortical cross-sectional area declines while the total area increases owing to periosteal apposition [35-37]. Thus, expansion of the outer diameter partially preserves the bone's ability to resist bending and torsion, although there is a net loss in the amount of bone mineral with aging [35, 37]. Our results suggest that a similar mechanism does not exist when the bone loss is caused by fracture since we found no higher cross-sectional area in the affected limb compared to the non-affected limb in the hip fracture patients. Therefore, it seems that although both aging and injuries cause bone loss, injury-induced bone loss may be more deleterious to bone strength than age-related bone loss.

It is noteworthy that side-to-side differences in knee extension strength and muscle crosssectional area of the lower leg systematically explained a large part of the side-to-side differences in bone mineral mass and geometry: the lower the muscle area or muscle strength in the fractured limb (compared to the non-fractured limb), the lower were the bone properties in the same limb (compared to the non-fractured limb). This is in line with previous findings 
that after hip fracture lean body mass $[18,23]$ and, more precisely, the thigh muscle volume in the fractured limb decreases [12]. Also, long-term bone loss of the injured limb has been reported to be associated with duration of immobilization as well as with reduction in muscle strength and limb function $[14,15]$. Thus, it seems that posttraumatic bone loss is caused, at least partly, by incomplete recovery of muscle function after the trauma. It is likely that because of disuse following the fracture and consequent reduced muscle strength, the mechanical loading on the injured leg decreases. The decreased strains causes then removal of bone [38], leading in turn to impaired bone mass and geometry. The results imply that by rehabilitation strategies aimed at preserving muscle tissue and muscle strength after hip fracture the injury-induced bone loss may be diminished. In contrast to conventional physical therapy, intensive resistance training has been shown to be effective in improving lower limb muscle strength after hip fracture [39, 40].

The main limitation of this study was the cross-sectional design, which does not allow the true changes taken place in the fractured limb to be measured. However, we used the side-to-side comparison design, which has the advantage of minimizing the effect of many confounding factors, such as age, genes, nutrition and drugs that might affect absolute bone values. Another limitation of our study was that the subjects were women with relatively good physical and cognitive functioning and therefore these results may not be directly applicable to other populations with previous hip fracture, such as men and people living in institutions. Although the statistical power was in general adequate, the sample size of this study may have been somewhat limited for detecting small between-group differences.

In conclusion, hip fracture results in significantly reduced bone mineral mass and impaired geometric properties in the tibia of the fractured limb. This reduction in the bone properties in 
the fractured limb may increase the risk of subsequent fractures. Good muscle function seems to be of great importance for good bone mass and geometry in older women with a hip fracture history. Longitudinal studies with follow-ups over several years are needed to determine the actual changes that occur in bone geometry after a hip fracture. 


\section{ACKOWLEDGEMENTS}

This study was supported by grants from the Finnish Ministry of Education, Peurunka Rehabilitation and Exercise Foundation and University of Jyväskylä. 


\section{REFERENCES}

1. Johnell O, Kanis JA (2004) An estimate of the worldwide prevalence, mortality and disability associated with hip fracture. Osteoporos Int 15:897-902

2. Johnell O (1997) The socioeconomic burden of fractures: today and in the 21st century. Am J Med 103:20S,25S; discussion 25S-26S

3. Borgström F, Zethraeus N, Johnell O, Lidgren L, Ponzer S, Svensson O, Abdon P, Ornstein E, Lunsjö K, Thorngren KG, Sernbo I, Rehnberg C, Jönsson B (2006) Costs and quality of life associated with osteoporosis-related fractures in Sweden. Osteoporos Int 17:637-50

4. Ethgen O, Tellier V, Sedrine WB, De Maeseneer J, Gosset C, Reginster JY (2003) Healthrelated quality of life and cost of ambulatory care in osteoporosis: how may such outcome measures be valuable information to health decision makers and payers? Bone 32:718-24

5. Chapurlat RD, Bauer DC, Nevitt M, Stone K, Cummings SR (2003) Incidence and risk factors for a second hip fracture in elderly women. The Study of Osteoporotic Fractures. Osteoporos Int 14:130-6

6. Colon-Emeric C, Kuchibhatla M, Pieper C, Hawkes W, Fredman L, Magaziner J, Zimmerman S, Lyles KW (2003) The contribution of hip fracture to risk of subsequent fractures: data from two longitudinal studies. Osteoporos Int 14:879-83

7. van Staa TP, Leufkens HG, Cooper C (2002) Does a fracture at one site predict later fractures at other sites? A British cohort study. Osteoporos Int 13:624-9 
8. Van der Wiel HE, Lips P, Nauta J, Patka P, Haarman HJ, Teule GJ (1994) Loss of bone in the proximal part of the femur following unstable fractures of the leg. J Bone Joint Surg Am $76: 230-6$

9. Zerahn B, Olsen C, Stephensen S, Kanstrup IL, Schwarz Lausten G (1998) Bone loss after hip fracture is correlated to the postoperative degree of mobilisation. Arch Orthop Trauma Surg 117:453-6

10. Petersen MM, Gehrchen PM, Nielsen PK, Lund B (1997) Loss of bone mineral of the hip assessed by DEXA following tibial shaft fractures. Bone 20:491-5

11. Eyres KS, Kanis JA (1995) Bone loss after tibial fracture. Evaluated by dual-energy X-ray absorptiometry. J Bone Joint Surg Br 77:473-8

12. Neander G, Adolphson P, Hedström M, von Sivers K, Dahlborn M, Dalen N (1997)

Decrease in bone mineral density and muscle mass after femoral neck fracture. A quantitative computed tomography study in 25 patients. Acta Orthop Scand 68:451-5

13. Karlsson MK, Nilsson BE, Obrant KJ (1993) Bone mineral loss after lower extremity trauma. 62 cases followed for 15-38 years. Acta Orthop Scand 64:362-4

14. Kannus P, Järvinen M, Sievänen H, Järvinen TA, Oja P, Vuori I (1994) Reduced bone mineral density in men with a previous femur fracture. J Bone Miner Res 9:1729-36

15. Kannus P, Järvinen M, Sievänen H, Oja P, Vuori I (1994) Osteoporosis in men with a history of tibial fracture. J Bone Miner Res 9:423-9

16. Findlay SC, Eastell R, Ingle BM (2002) Measurement of bone adjacent to tibial shaft fracture. Osteoporos Int 13:980-9 
17. Järvinen M, Kannus P (1997) Injury of an extremity as a risk factor for the development of osteoporosis. J Bone Joint Surg Am 79:263-76

18. Karlsson M, Nilsson JA, Sernbo I, Redlund-Johnell I, Johnell O, Obrant KJ (1996)

Changes of bone mineral mass and soft tissue composition after hip fracture. Bone 18:19-22

19. Magaziner J, Wehren L, Hawkes WG, Orwig D, Hebel JR, Fredman L, Stone K, Zimmerman S, Hochberg MC (2006) Women with hip fracture have a greater rate of decline in bone mineral density than expected: another significant consequence of a common geriatric problem. Osteoporos Int 17:971-7

20. van der Poest Clement,E., van der Wiel H, Patka P, Roos JC, Lips P (1999) Long-term consequences of fracture of the lower leg: cross-sectional study and long-term longitudinal follow-up of bone mineral density in the hip after fracture of lower leg. Bone 24:131-4

21. Dirschl DR, Henderson RC, Oakley WC (1997) Accelerated bone mineral loss following a hip fracture: a prospective longitudinal study. Bone 21:79-82

22. Dirschl DR, Piedrahita L, Henderson RC (2000) Bone mineral density 6 years after a hip fracture: a prospective, longitudinal study. Bone 26:95-8

23. Fox KM, Magaziner J, Hawkes WG, Yu-Yahiro J, Hebel JR, Zimmerman SI, Holder L, Michael R (2000) Loss of bone density and lean body mass after hip fracture. Osteoporos Int $11: 31-5$

24. Järvinen TL, Sievänen H, Jokihaara J, Einhorn TA (2005) Revival of bone strength: the bottom line. J Bone Miner Res 20:717-20 
25. Bråten M, Nordby A, Terjesen T, Rossvoll I (1992) Bone loss after locked intramedullary nailing. Computed tomography of the femur and tibia in 10 cases. Acta Orthop Scand 63:3104

26. Terjesen T, Nordby A, Arnulf V (1985) Bone atrophy after plate fixation. Computed tomography of femoral shaft fractures. Acta Orthop Scand 56:416-8

27. Haapasalo H, Kontulainen S, Sievänen H, Kannus P, Järvinen M, Vuori I (2000) Exerciseinduced bone gain is due to enlargement in bone size without a change in volumetric bone density: a peripheral quantitative computed tomography study of the upper arms of male tennis players. Bone 27:351-7

28. Adami S, Gatti D, Braga V, Bianchini D, Rossini M (1999) Site-specific effects of strength training on bone structure and geometry of ultradistal radius in postmenopausal women. J Bone Miner Res 14:120-4

29. Sievänen H, Koskue V, Rauhio A, Kannus P, Heinonen A, Vuori I (1998) Peripheral quantitative computed tomography in human long bones: evaluation of in vitro and in vivo precision. J Bone Miner Res 13:871-82

30. Sipilä S, Multanen J, Kallinen M, Era P, Suominen H (1996) Effects of strength and endurance training on isometric muscle strength and walking speed in elderly women. Acta Physiol Scand 156:457-64

31. Sone T, Imai Y, Joo YI, Onodera S, Tomomitsu T, Fukunaga M (2006) Side-to-side differences in cortical bone mineral density of tibiae in young male athletes. Bone 38:708-13

32. Veitch SW, Findlay SC, Hamer AJ, Blumsohn A, Eastell R, Ingle BM (2006) Changes in bone mass and bone turnover following tibial shaft fracture. Osteoporos Int 17:364-72 
33. Allen MR, Bloomfield SA (2003) Hindlimb unloading has a greater effect on cortical compared with cancellous bone in mature female rats. J Appl Physiol 94:642-50

34. Kontulainen S, Sievänen H, Kannus P, Pasanen M, Vuori I (2002) Effect of long-term impact-loading on mass, size, and estimated strength of humerus and radius of female racquet-sports players: a peripheral quantitative computed tomography study between young and old starters and controls. J Bone Miner Res 17:2281-9

35. Russo CR, Lauretani F, Bandinelli S, Bartali B, Di Iorio A, Volpato S, Guralnik JM, Harris T, Ferrucci L (2003) Aging bone in men and women: beyond changes in bone mineral density. Osteoporos Int 14:531-8

36. Seeman E (1997) From density to structure: growing up and growing old on the surfaces of bone. J Bone Miner Res 12:509-21

37. Ahlborg HG, Johnell O, Turner CH, Rannevik G, Karlsson MK (2003) Bone loss and bone size after menopause. N Engl J Med 349:327-34

38. Frost HM (2000) The Utah paradigm of skeletal physiology: an overview of its insights for bone, cartilage and collagenous tissue organs. J Bone Miner Metab 18:305-16

39. Binder EF, Brown M, Sinacore DR, Steger-May K, Yarasheski KE, Schechtman KB (2004) Effects of extended outpatient rehabilitation after hip fracture: a randomized controlled trial. JAMA 292:837-46

40. Hauer K, Specht N, Schuler M, Bartsch P, Oster P (2002) Intensive physical training in geriatric patients after severe falls and hip surgery. Age Ageing 31:49-57 
Table 1 Characteristics of the hip fracture patients and controls. Values are given as mean (SD).

\begin{tabular}{lccc}
\hline & Hip fracture patients $(\mathrm{n}=37)$ & Controls $(\mathrm{n}=22)$ & $\mathrm{p}^{\mathrm{a}}$ \\
\hline Age (years) & $76.0(6.1)$ & $73.5(6.4)$ & 0.147 \\
Body weight (kg) & $66.6(11.6)$ & $68.7(9.2)$ & 0.465 \\
Height (cm) & $159.7(6.2)$ & $158.1(6.0)$ & 0.333 \\
Number of chronic diseases & $4(2)$ & $4(2)$ & 0.945 \\
Radius BMC (mg/mm) & $91.1(15.5)$ & $93.8(14.4)$ & 0.541 \\
Time since hip fracture (years) & $3.5(2.0)$ & - & - \\
\hline
\end{tabular}

${ }^{\mathrm{a}}$ T-test for independent samples

BMC, bone mineral content 
Table 2 Bone properties in the hip fracture patients and controls and side-to-side differences between limbs. The values are given as mean (SD).

\begin{tabular}{|c|c|c|c|c|c|c|c|c|c|}
\hline & \multicolumn{4}{|c|}{ Hip fracture patients $(n=37)$} & \multicolumn{4}{|l|}{ Controls (n=22) } & \multirow[b]{2}{*}{$p^{d}$} \\
\hline & $\begin{array}{l}\text { Fractured } \\
\text { side }\end{array}$ & $\begin{array}{c}\text { Non-fractured } \\
\text { side }\end{array}$ & $\begin{array}{c}\text { \% mean } \\
\text { side-to-side } \\
\text { difference }^{\mathrm{a}, \mathrm{c}}\end{array}$ & $95 \% \mathrm{CI}$ & $\begin{array}{l}\text { Dominant } \\
\text { side }\end{array}$ & $\begin{array}{c}\text { Non-dominant } \\
\text { side }\end{array}$ & $\begin{array}{c}\text { \% mean } \\
\text { side-to-side } \\
\text { difference }^{\text {b,c }}\end{array}$ & $95 \% \mathrm{CI}$ & \\
\hline \multicolumn{10}{|l|}{ Tibial shaft } \\
\hline $\mathrm{BMC}(\mathrm{mg} / \mathrm{mm})$ & $297(55)$ & $311(49)$ & -4.9 & -7.0 to -2.7 & $337(41)$ & $339(45)$ & -0.5 & -3.3 to 2.4 & 0.018 \\
\hline $\mathrm{CoD}\left(\mathrm{mg} / \mathrm{cm}^{3}\right)$ & 985 (82) & 996 (69) & -1.2 & -2.4 to 0.0 & 1018 (38) & $1018(43)$ & 0.1 & -1.5 to 1.7 & 0.203 \\
\hline ToA $\left(\mathrm{mm}^{2}\right)$ & $473(48)$ & $478(54)$ & -0.8 & -2.4 to 0.7 & $485(43)$ & 481 (39) & 0.5 & -1.6 to 2.6 & 0.309 \\
\hline $\operatorname{CoA}\left(\mathrm{mm}^{2}\right)$ & $240(41)$ & 253 (37) & -5.2 & -7.4 to -3.0 & $278(38)$ & $278(41)$ & 0.1 & -2.8 to 3.1 & 0.005 \\
\hline $\mathrm{I}_{\text {polar }}(\mathrm{mg} \mathrm{cm})$ & 3221 (702) & 3417 (697) & -5.6 & -8.5 to -2.7 & 3610 (598) & $3656(660)$ & -0.8 & -4.6 to 3.1 & 0.050 \\
\hline \multicolumn{10}{|l|}{ Distal tibia } \\
\hline $\mathrm{BMC}(\mathrm{mg} / \mathrm{mm})$ & $228(44)$ & $239(44)$ & -5.1 & -7.2 to -3.0 & $264(40)$ & $268(40)$ & -1.4 & -4.2 to 1.3 & 0.041 \\
\hline $\operatorname{TrD}\left(\mathrm{mg} / \mathrm{cm}^{3}\right)$ & $178(50)$ & $181(49)$ & -1.9 & -4.7 to 0.8 & $209(44)$ & $208(42)$ & 1.2 & -2.4 to 4.9 & 0.179 \\
\hline ToA $\left(\mathrm{mm}^{2}\right)$ & $1094(121)$ & $1116(115)$ & -1.9 & -3.3 to -0.4 & 1055 (107) & $1060(98)$ & -0.6 & -2.6 to 1.4 & 0.304 \\
\hline $\mathrm{I}_{\text {polar }}(\mathrm{mg} \mathrm{cm})$ & 4574 (1037) & $4963(1102)$ & -7.5 & -10.4 to -4.7 & 5187 (1019) & $5313(998)$ & -2.4 & -6.2 to 1.4 & 0.036 \\
\hline
\end{tabular}

${ }^{\text {a }}$ Side-to-side difference $=($ fractured-nonfractured $) /$ nonfractured $* 100$

bide-to-side difference $=($ dominant-nondominant $) /$ nondominant $* 100$

${ }^{\mathrm{c}}$ Adjusted with age and weight

${ }^{\mathrm{d}}$ Analysis of covariance of side-to-side differences in tibia between the groups, age and weight as covariates

BMC, bone mineral content; CoD, cortical bone mineral density; ToA, total cross-sectional area; CoA, cortical cross-sectional area; $\mathrm{I}_{\text {polar }}$, polar moment of inertia;

TrD, trabecular bone mineral density 
Table 3 Associations between possible predictive variables and side-to-side differences in bone variables. Pearson's correlation coefficient (p-value).

\begin{tabular}{|c|c|c|c|c|c|c|}
\hline & Age & Weight & $\begin{array}{l}\text { Time } \\
\text { since } \\
\text { fracture }\end{array}$ & $\begin{array}{c}\text { Knee } \\
\text { extension } \\
\text { strength }^{\mathrm{a}}\end{array}$ & $\begin{array}{c}\text { Muscle } \\
\text { CSA }^{\mathrm{a}}\end{array}$ & $\begin{array}{c}\text { Maximal } \\
\text { walking } \\
\text { speed }\end{array}$ \\
\hline \multicolumn{7}{|c|}{ Tibial shaft } \\
\hline $\mathrm{BMC}^{\mathrm{a}}$ & $\begin{array}{c}-0.02 \\
(0.918)\end{array}$ & $\begin{array}{c}0.21 \\
(0.204)\end{array}$ & $\begin{array}{c}0.08 \\
(0.649)\end{array}$ & $\begin{array}{c}0.42 \\
(0.011)\end{array}$ & $\begin{array}{c}0.47 \\
(0.010)\end{array}$ & $\begin{array}{c}-0.10 \\
(0.581)\end{array}$ \\
\hline $\mathrm{CoA}^{\mathrm{a}}$ & $\begin{array}{c}-0.01 \\
(0.946)\end{array}$ & $\begin{array}{c}-0.24 \\
(0.149)\end{array}$ & $\begin{array}{c}-0.01 \\
(0.948)\end{array}$ & $\begin{array}{c}0.29 \\
(0.083)\end{array}$ & $\begin{array}{c}0.39 \\
(0.036)\end{array}$ & $\begin{array}{c}-0.05 \\
(0.775)\end{array}$ \\
\hline $\mathrm{I}_{\text {polar }}^{\mathrm{a}}$ & $\begin{array}{c}-0.08 \\
(0.624)\end{array}$ & $\begin{array}{c}-0.21 \\
(0.204)\end{array}$ & $\begin{array}{c}0.06 \\
(0.748)\end{array}$ & $\begin{array}{c}0.47 \\
(0.004)\end{array}$ & $\begin{array}{c}0.46 \\
(0.011)\end{array}$ & $\begin{array}{c}-0.14 \\
(0.427)\end{array}$ \\
\hline Distal $t$ & & & & & & \\
\hline $\mathrm{BMC}^{\mathrm{a}}$ & $\begin{array}{c}0.18 \\
(0.278)\end{array}$ & $\begin{array}{c}-0.10 \\
(0.574)\end{array}$ & $\begin{array}{c}0.27 \\
(0.110)\end{array}$ & $\begin{array}{c}0.50 \\
(0.002)\end{array}$ & $\begin{array}{c}0.25 \\
(0.188)\end{array}$ & $\begin{array}{c}0.05 \\
(0.770)\end{array}$ \\
\hline $\mathrm{I}_{\text {polar }}^{\mathrm{a}}$ & $\begin{array}{c}0.16 \\
(0.357)\end{array}$ & $\begin{array}{c}0.02 \\
(0.917)\end{array}$ & $\begin{array}{c}0.29 \\
(0.077)\end{array}$ & $\begin{array}{c}0.44 \\
(0.008)\end{array}$ & $\begin{array}{c}0.20 \\
(0.284)\end{array}$ & $\begin{array}{c}0.06 \\
(0.745)\end{array}$ \\
\hline
\end{tabular}

${ }^{\mathrm{a}}$ Side-to-side difference variable

BMC, bone mineral content; CoA, cortical cross-sectional area; $\mathrm{I}_{\text {polar }}$, polar moment of inertia; muscle CSA, cross-sectional area of lower leg muscles 
Table 4 Adjusted regression models ${ }^{\mathrm{a}}$ for side-to-side differences in bone variables in hip fracture patients $(\mathrm{N}=37)$.

\begin{tabular}{|c|c|c|c|c|}
\hline Dependent variables ${ }^{\mathrm{b}}$ & Predictors $^{\mathrm{b}}$ & $\beta$ & $\mathrm{p}$ & $\mathrm{R}^{2}$ \\
\hline \multirow[t]{2}{*}{ Tibial shaft BMC } & Knee extension strength & 0.39 & 0.020 & \\
\hline & Muscle CSA & 0.42 & 0.021 & 0.37 \\
\hline \multirow[t]{2}{*}{ Tibial shaft CoA } & Knee extension strength & 0.26 & 0.154 & \\
\hline & Muscle CSA & 0.42 & 0.035 & 0.23 \\
\hline \multirow[t]{2}{*}{ Tibial shaft $I_{\text {polar }}$} & Knee extension strength & 0.41 & 0.010 & \\
\hline & Muscle CSA & 0.51 & 0.004 & 0.44 \\
\hline \multirow[t]{2}{*}{ Distal tibia BMC } & Knee extension strength & 0.45 & 0.010 & \\
\hline & Muscle CSA & 0.32 & 0.082 & 0.34 \\
\hline \multirow[t]{2}{*}{ Distal tibia $\mathrm{I}_{\text {polar }}$} & Knee extension strength & 0.36 & 0.035 & \\
\hline & Muscle CSA & 0.33 & 0.073 & 0.26 \\
\hline
\end{tabular}

\footnotetext{
${ }^{\mathrm{a}}$ Adjusted with time since fracture

${ }^{\mathrm{b}}$ Side-to-side difference variables

BMC, bone mineral content; CoA, cortical cross-sectional area; $\mathrm{I}_{\text {polar }}$, polar moment of inertia; muscle CSA, cross-sectional area of lower leg muscles
} 